\title{
Study on the Dynamic Evolution of Through-Crack in the Double Hole of Elliptical Bipolar Linear-Shaped Charge Blasting
}

\author{
Bo Wu, ${ }^{1,2,3}$ Shixiang Xu $\mathbb{D}^{1},{ }^{1}$ Guowang Meng $\mathbb{D D}^{1}{ }^{1}$ Yaozhong Cui, ${ }^{1}$ Junhua Cai ${ }^{\mathbb{D}},{ }^{4}$ \\ and Yao Zhang ${ }^{5}$ \\ ${ }^{1}$ College of Civil Engineering and Architecture, Guangxi University, Nanning, Guangxi 530004, China \\ ${ }^{2}$ School of Civil and Architectural Engineering, East China University of Technology, Nanchang, Jiangxi 330013, China \\ ${ }^{3}$ School of Architectural Engineering, Guangzhou City Construction College, Guangzhou, Guangdong 510925, China \\ ${ }^{4}$ Sanming Puyan Expressway Co., Ltd., Sanming, Fujian 365000, China \\ ${ }^{5}$ China Railway 11th Bureau Group First Engineering Co. Ltd., Xiangyang 441104, China \\ Correspondence should be addressed to Shixiang Xu; 603559081@qq.com
}

Received 9 July 2021; Accepted 10 August 2021; Published 18 August 2021

Academic Editor: Zhigang Tao

Copyright $\odot 2021$ Bo Wu et al. This is an open access article distributed under the Creative Commons Attribution License, which permits unrestricted use, distribution, and reproduction in any medium, provided the original work is properly cited.

\begin{abstract}
Seeking the law of through-crack in the double hole of shaped charge can help reveal the rock failure mechanism of directional controlled blasting. Using LS-DYNA numerical simulation analysis, the dynamic mechanical behaviors of double-hole crack development and double-hole crack penetration in elliptical bipolar linear-shaped charge blasting and ordinary blasting were compared and studied. The results showed that it was difficult to form a straight line through the double holes under ordinary blasting, while easy to cause over-under-excavation problems. The blasting of the elliptical bipolar linear-shaped charge had a significant effect on the formation of directional crack. The crack penetrated along the connecting center line of the two holes. The main crack growth form was tensile fracture mode, and the explosion gas was the important driving force for continuous crack growth. The elliptical bipolar linear-shaped charge blasting produced fewer cracks in the nonenergy-accumulating direction, which could effectively reduce the damage of the retained rock mass.
\end{abstract}

\section{Introduction}

The directional fracture controlled blasting of shaped charge changes the structure of the explosive itself and utilizes the energy gathering effect of the energy cavity to form a stream of explosive products with high velocity and pressure after blasting, which directly acts on the wall of the blast hole and makes the rock crack and expand preferentially in the concentrating energy direction and then achieves the purpose of directional fracture blasting. In recent years, scholars at home and abroad have carried out relevant theoretical research, experimental research, and numerical simulation analysis on directional fracture controlled blasting technology. Cho et al. [1] studied the effect of the location of the guide hole and the initiation time lag on the crack propagation control and analyzed the relationship between the applied fracture energy and crack extension. Yang and Wang et al. [2-5] explored the influence of different cutting angle, depth, and other factors on blasting crack propagation by using a testing system of digital laser dynamic caustics, and specific tests were carried out on the extension and penetration mechanism of cracks. Yue et al. [6-10] analyzed the influence of different intervals between holes of explosive load on the crack propagation through the dynamic caustics test and numerical simulation, which indicated that the growth rate of the main blasting crack, the peak value of the dynamic stress intensity factor, and the stress peak value of the crack meeting area all depended on the blast hole spacing. When the distance between holes is small, the peak value is large, which is conducive to the directional expansion of cracks. Zhang et al. [11] studied the influence of the material of the cut tube and the decoupling coefficient on the crack growth through the mortar model test. He et al. developed a new material of constant resistance and large 
deformation bolt in deep rock mass [12] and developed the technology and equipment of energy-gathered roof cutting in deep rock mass, which has achieved precise control of blasting crack propagation and ensured the molding quality around the roadway $[13,14]$. Luo et al. $[15,16]$ based on dynamics of explosion and fracture mechanics studied the mechanism of crack initiation and its expansion of directional fracture controlled blasting by shaped charge with wedge-type liners in rock. Guo et al. [17-19] analyzed the dynamic effect of deep hole-shaped charge blasting and considered that the shaped charge effect of deep hole-shaped charge blasting significantly changed the propagation characteristics of explosion stress wave and the mechanical properties of rock mass. Wu et al. [20-23] conducted a preliminary study on the influencing factor of the formation of the elliptical bipolar line-shaped charge jet and the mechanism of initial crack formation.

However, the stress wave propagation and crack development of single-hole blasting and double-hole blasting are different in shaped charge blasting. To date, there are few studies on the stress wave propagation and crack development law of surrounding rock of shaped energy double-hole blasting. Therefore, this paper combined the theoretical analysis with the numerical simulation to study the stress wave propagation and crack development law of doublehole blasting based on the elliptical bipolar linear-shaped charge blasting technology, whilst compared with those of ordinary blasting. The results are of great significance to the research and application of the technology.

\section{Stress Wave Propagation and Crack Mechanism of Shaped Charge Blasting}

2.1. Mechanism Analysis of Crack Development in Shaped Charge Blasting. The elliptical bipolar linear-shaped charge blasting technology makes full use of the tensile failure characteristics of rock. Through the combination of PVC shaped charge pipe and explosive, the tangential tensile stress is formed in the concentrating energy direction after the explosion, and the detonation pressure is transformed into the tensile effect on surrounding rock, forming effective directional precracking in the concentrating energy direction. At the same time, due to the buffering effect of PVC pipe in the nonconcentrated energy direction, the damage of rock on the blast hole wall in the nonconcentrated energy direction is avoided. The principle of elliptical bipolar linearshaped charge blasting and the schematic diagram of shaped charge are shown in Figure 1.

\subsection{Fracture Mechanism of Double Hole-Shaped Charge} Blasting. In continuous-hole-shaped charge blasting, two adjacent blast holes are detonated simultaneously, and the explosion stress wave propagates to the midpoint of the line connecting the blast hole and superimposes at the midpoint of the line of the two blast holes. Due to a certain energy loss in the propagation of wave and explosive gas in the rock, when the tensile stress at each point of the connecting line in the concentrating energy direction of the adjacent blast holes is greater than or equal to the tensile strength of the rock, the cracks between the adjacent blast holes can be connected [24]. The mechanical model of the elliptical bipolar linearshaped charge blasting continuous hole is shown in Figure 2.

As shown in Figure 2, during continuous-hole-shaped charge blasting, the explosive gas enters from the concentrating energy direction of two blasting holes, respectively, for expansion and extrusion. However, the stress superposition surface would be generated at the vertical line of the midpoint of the concentrating energy direction line of two blasting holes in the process of stress wave propagation. Although there is energy loss in the process of stress wave propagation, according to the superposition principle of wave, a tensile stress of 2 times is generated at the stress superposition surface, which can appropriately increase the distance between the two blast holes.

\section{Validation of Numerical Solution}

3.1. Numerical Model. LS-DYNA was used to carry out numerical simulation analysis. The explosive material model in LS-DYNA was characterized by MAT_HIGH_EXPLOSIVE_BURN, and the JWL equation was adopted to describe the relationship between the pressure and volume of the explosive after detonation.

$$
p=A\left(1-\frac{\omega}{R_{1} V}\right) e^{-R_{1} V}+B\left(1-\frac{\omega}{R_{2} V}\right)+\frac{\omega E}{V},
$$

where $p$ is the pressure, $A, B, \omega, R_{1}$, and $R_{2}$ are the basic parameters of the equation of state, $V$ is the relative volume of the detonation product, and $E$ is the initial internal energy density of the detonation product. Properties of explosive and JWL state equation are shown in Table 1.

The mechanical parameter of the shaped charge cover is shown in Table 2.

The HJC constitutive model was used for rock material. The MAT_ADD_EROSION damage criterion was used to determine the damage condition of each element in the simulation of fracture development [25]. The mechanical parameters of rock in the model are shown in Table 3, and the maximum principal stress failure of rock is defined to analyze the crack development.

3.2. Explosion Test of PMMA. PMMA is often used as an ideal experimental material to study the crack initiation process under blasting loading. Its fracture mechanics behavior is similar to that of brittle rock [26, 27]. Che [28] carried out the experimental research on the blasting test of shaped charge with PMMA. The shaped charge cover is a PVC hard plastic tube, with an inner diameter of $0.5 \mathrm{~cm}$. The shaped charge cover thickness is $0.1 \mathrm{~cm}$. The diameter of the blast hole is $1.2 \mathrm{~cm}$, as shown in Figure 3 .

3.3. Comparison between Simulation Results and Experimental Results. By establishing the same numerical analysis model as the experiment, the results of numerical simulation and experiment are shown in Figure 4. The numerical 


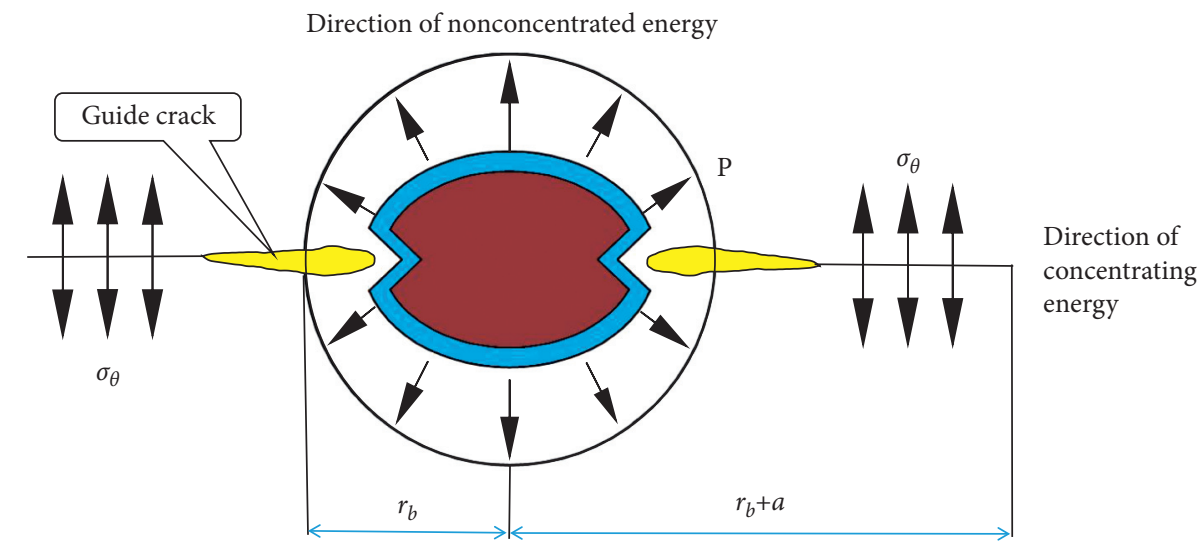

FIGURE 1: Mechanical model of cracking due to shaped charge blasting [23].

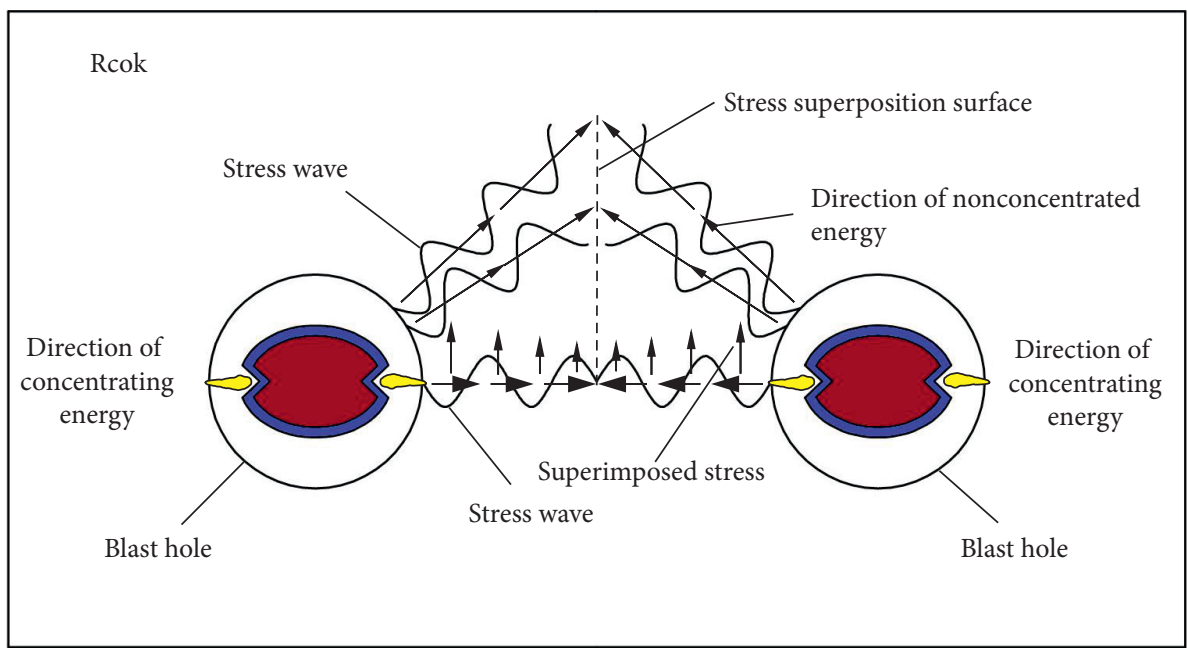

Figure 2: Mechanical model of continuous hole due to shaped charge blasting.

TABLE 1: Explosive and parameters of equation of state [23].

\begin{tabular}{lccccccc}
\hline $\begin{array}{l}\rho \\
\left(\mathrm{g} \cdot \mathrm{cm}^{-3}\right)\end{array}$ & $\begin{array}{c}\nu_{\mathrm{D}} \\
\left(\mathrm{cm} \cdot \mu \mathrm{s}^{-1}\right)\end{array}$ & $\begin{array}{c}A \\
(\mathrm{GPa})\end{array}$ & $\begin{array}{c}B \\
(\mathrm{GPa})\end{array}$ & $R_{1}$ & $R_{2}$ & $\omega$ & $\begin{array}{c}E \\
(\mathrm{GPa})\end{array}$ \\
\hline 1.3 & 0.4 & 214.4 & 0.182 & 4.2 & 0.9 & 0.15 & 4.192 \\
\hline
\end{tabular}

TABLE 2: Mechanical parameter of the shaped charge cover [23].

\begin{tabular}{lccc}
\hline Material & $\begin{array}{c}\text { Density } \\
\left(\mathrm{g} \cdot \mathrm{cm}^{-3}\right)\end{array}$ & $\begin{array}{c}\text { Elastic modulus } \\
(\mathrm{GPa})\end{array}$ & $\begin{array}{c}\text { Poisson's ratio } \\
(\mu)\end{array}$ \\
\hline PVC & 1.3 & 3.0 & 0.38 \\
\hline
\end{tabular}

TABLE 3: Material parameters of rock [23].

\begin{tabular}{lcc}
\hline Parameters & Property & Value \\
\hline$\rho\left(\mathrm{g} \cdot \mathrm{cm}^{-3}\right)$ & Density & 2.18 \\
$G(\mathrm{GPa})$ & Shear modulus & 14.86 \\
$A$ & Normalized cohesive strength & 0.79 \\
$B$ & Normalized pressure hardening & 1.60 \\
$C$ & Strain rate coefficient & 0.007 \\
$S_{\text {fmax }}$ & Normalized maximum strength & 7 \\
$\varepsilon_{\text {fmin }}$ & Amount of plastic strain before fracture & 0.01 \\
$N$ & Pressure hardening exponent & 0.61 \\
$D_{1}$ & Damage constant 1 & 0.04 \\
$D_{2}$ & Damage constant 2 & 1 \\
\hline
\end{tabular}

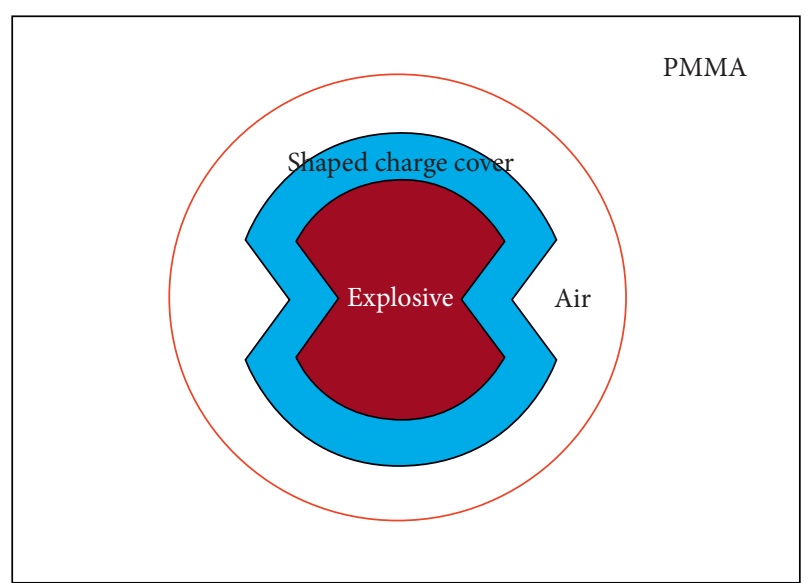

Figure 3: PMMA-shaped charge blasting [28].

simulation results perfectly reproduced the test process, the crack development was basically consistent with the test results at $80 \mu \mathrm{s}$ and $600 \mu \mathrm{s}$, and the final distribution pattern of rock crack is consistent with the test results. It was concluded that LS-DYNA could effectively simulate the 


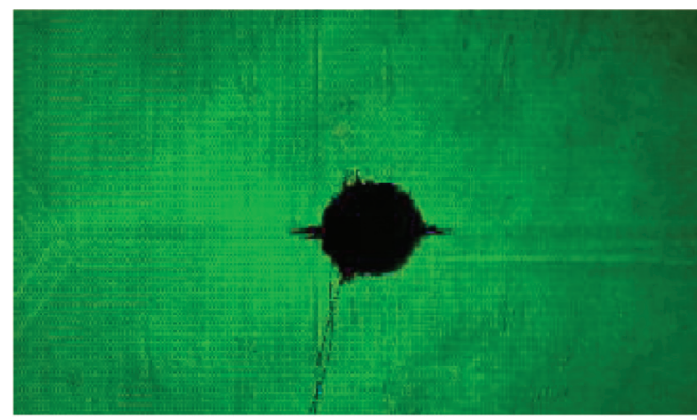

(a)

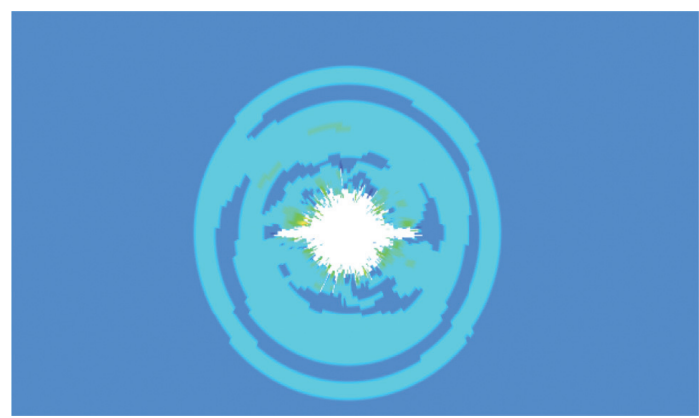

(c)

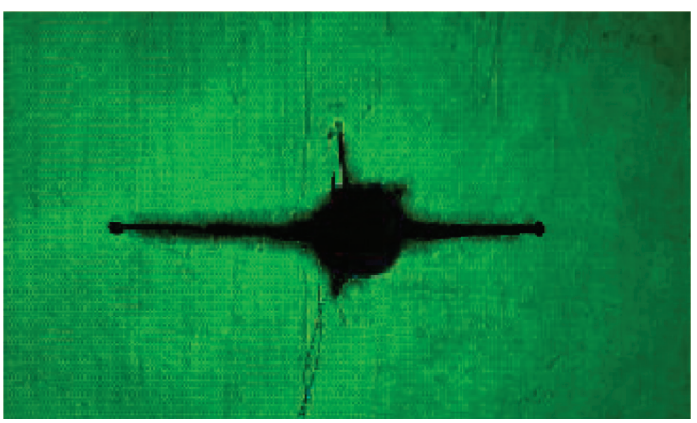

(b)

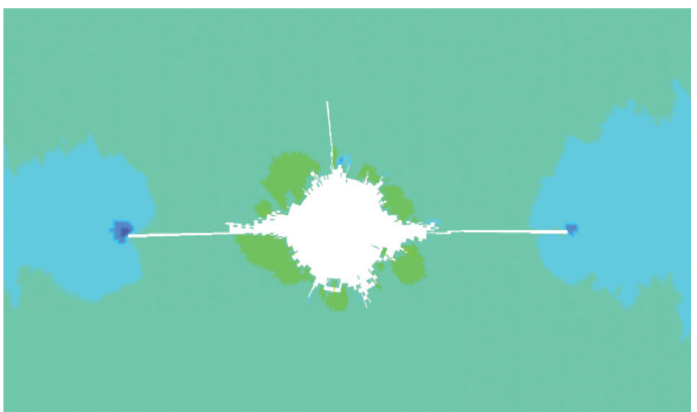

(d)

Figure 4: Comparison of the simulation results and experiment results (a) at $80 \mu \mathrm{s}$ of experiment results [28]; (b) at $600 \mu \mathrm{s}$ of experiment results [28]; (c) at $80 \mu \mathrm{s}$ of simulation results; (d) at $600 \mu \mathrm{s}$ of simulation results.

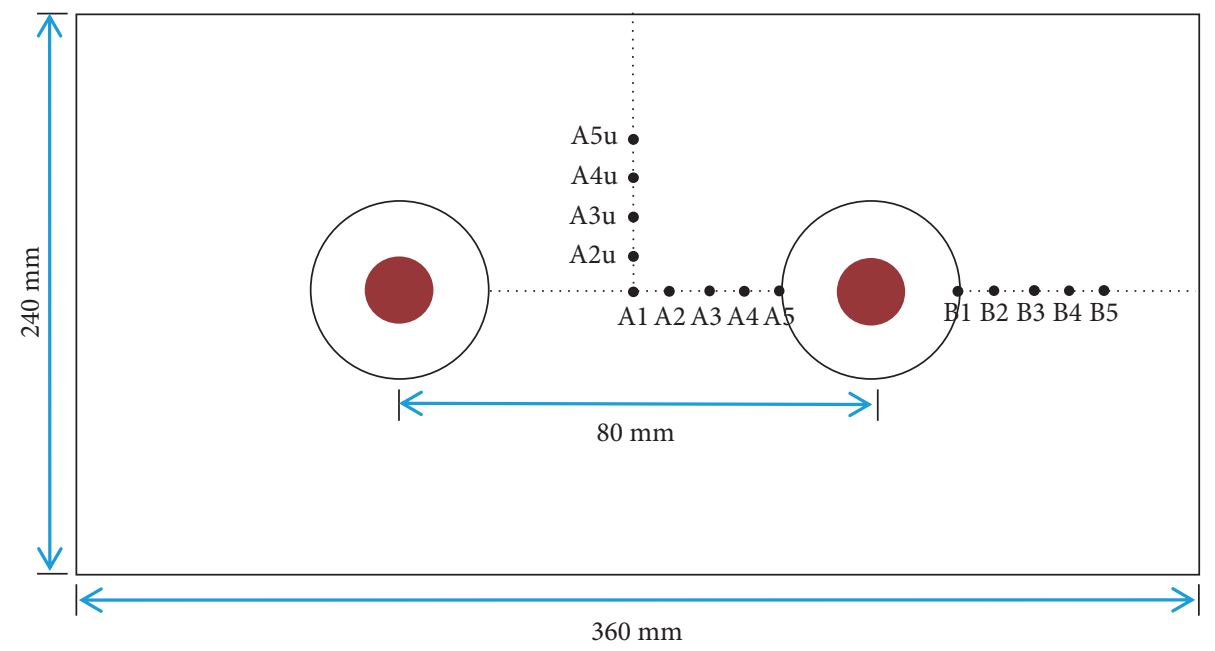

FIGURE 5: Schematic diagram of numerical calculation.

crack development process of rock in the shaped charge blasting process.

\section{Numerical Model of Elliptic Bipolar Linear- Shaped Charge Blasting}

4.1. Geometric Model of Numerical Calculation. The calculation models of double-hole ordinary blasting and elliptical bipolar linear shaped charge blasting with $90 \mathrm{~mm}$ hole diameter were established, respectively, as shown in Figures 5 and 6 . The charge mass of the two models is equal, the energy gathering tube is made of PVC material, the thickness of the shell of the energy gathering tube is $2 \mathrm{~mm}$, the thickness of the layer liner is $1.4 \mathrm{~mm}$, and the angle of the shaped charge groove is 70 degrees. Rock mass implies Lagrange unit, and other various materials imply the fluid-solid coupled algorithm. Nonreflecting boundary condition is applied around the model. The layout of measuring points is shown in Figures 5 and 6. Thereinto, A1 measuring point is in the center of the model, and the distance between each two adjacent measuring points is equal. 


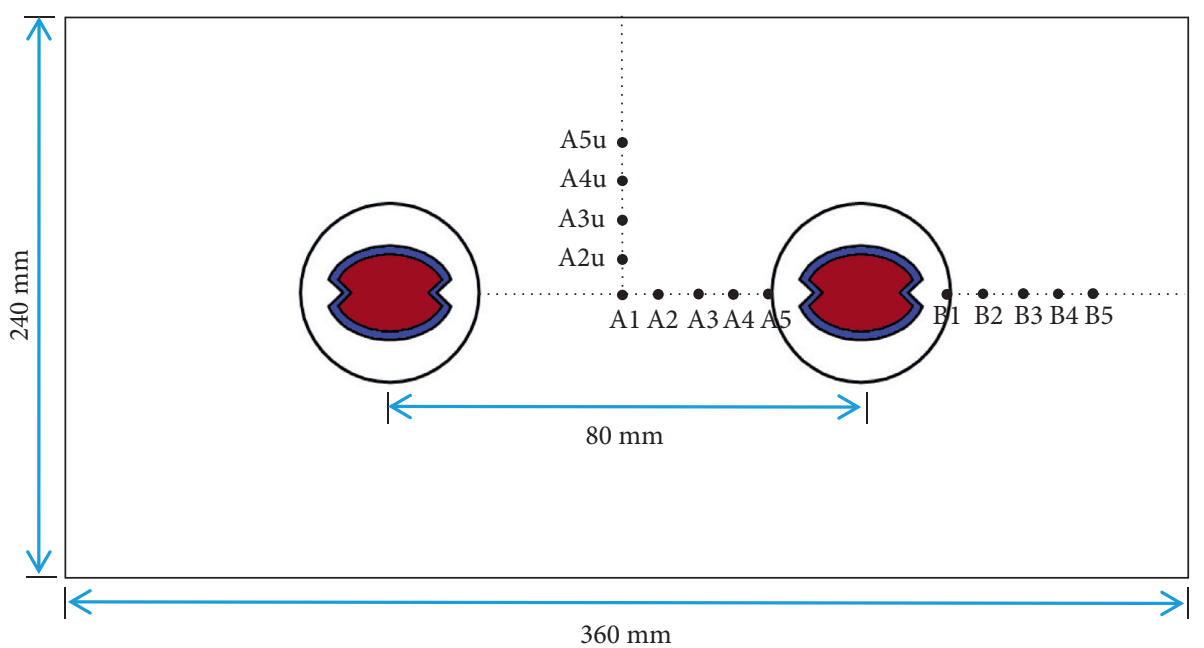

FIGURE 6: Schematic diagram of the numerical calculation model for the ordinary blasting model for shaped charge blasting.

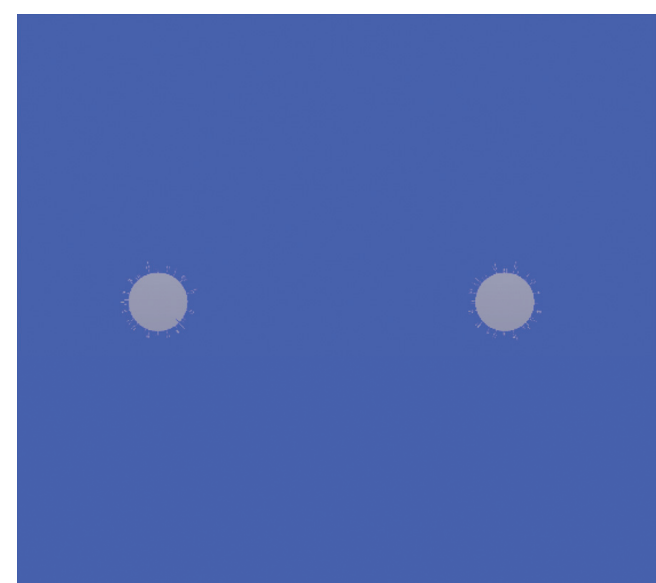

FIGURE 7: Crack development at $30 \mu$ s of ordinary blasting.

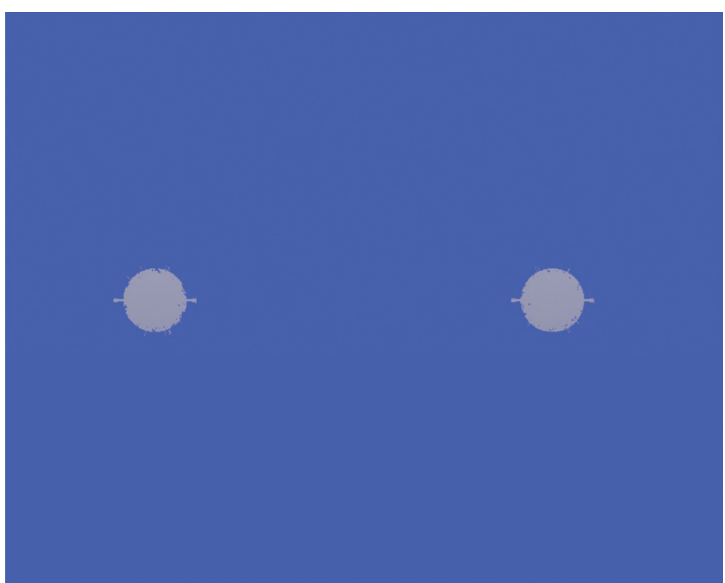

FIGURE 8: Crack development at $30 \mu$ s of shaped charge blasting.

4.2. Blasting Crack Development. Under ordinary blasting, after the explosives detonate, the detonation product is scattered randomly around the blasthole. Under shaped charge blasting, after the explosives detonate, the detonation wave acts on the shaped charge cover with huge pressure to

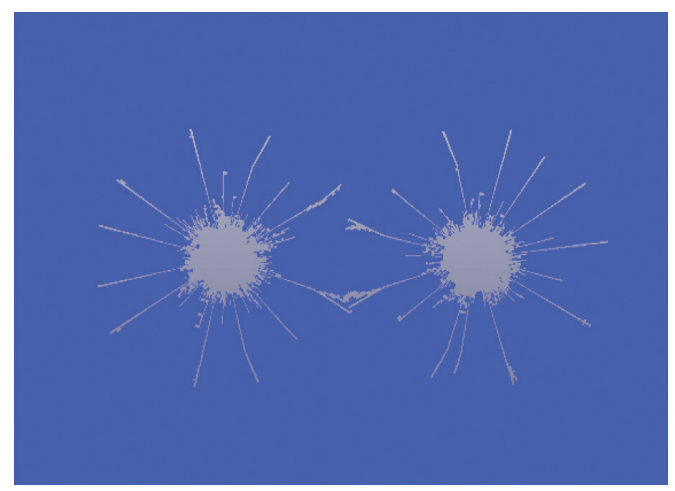

FIGURE 9: Crack penetration of ordinary blasting.

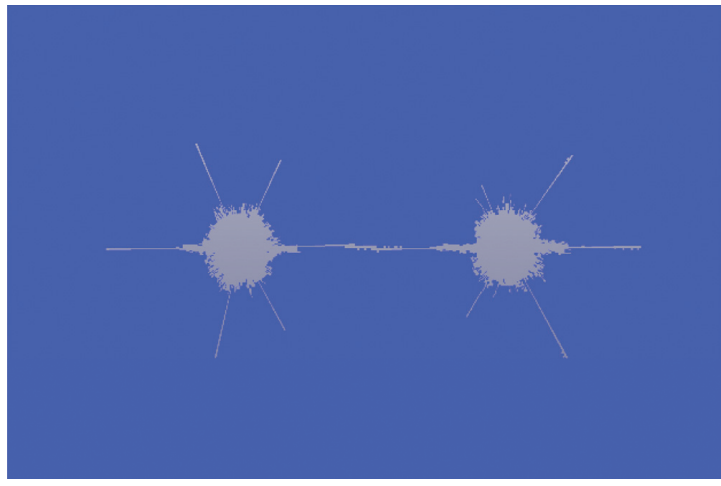

FIGURE 10: Crack penetration of shaped charge blasting.

form a shaped charge jet with high temperature, high pressure, and high energy, and the jet acts on the rock to form guiding crack. At $30 \mu \mathrm{s}$, the cracks develop irregularly in multiple directions under ordinary blasting, as shown in Figure 7, and the shaped charge blasting mainly develops along the concentrating energy direction, as shown in Figure 8 .

At $190 \mu \mathrm{s}$, the two cracks of ordinary blasting form a breakthrough, as shown in Figure 9. At $228 \mu \mathrm{s}$, the two main cracks of shaped charge blasting form a breakthrough, as 


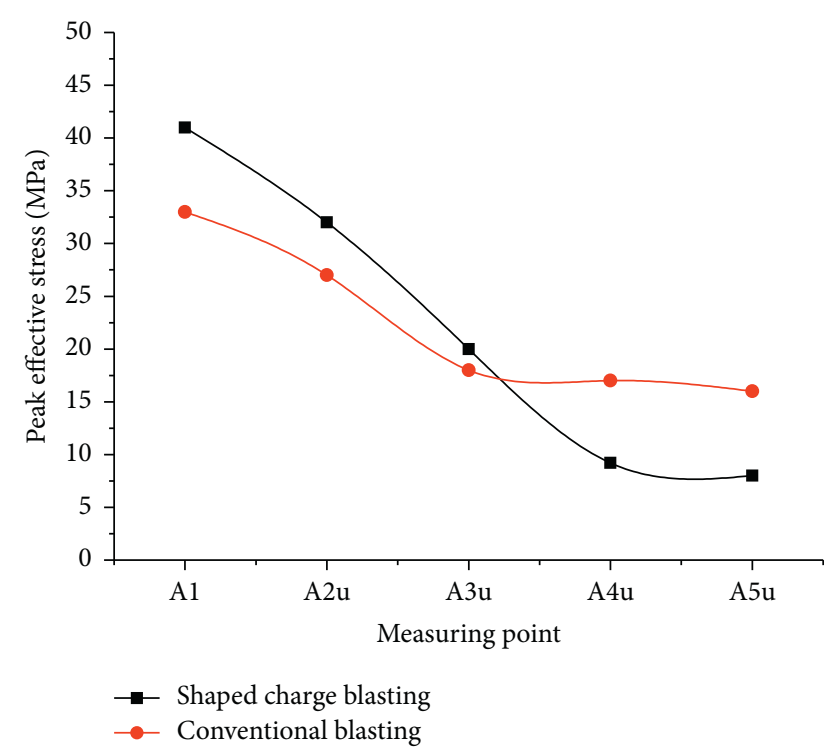

FIGURE 11: Peak effective stress of measuring point at the blast hole center line.

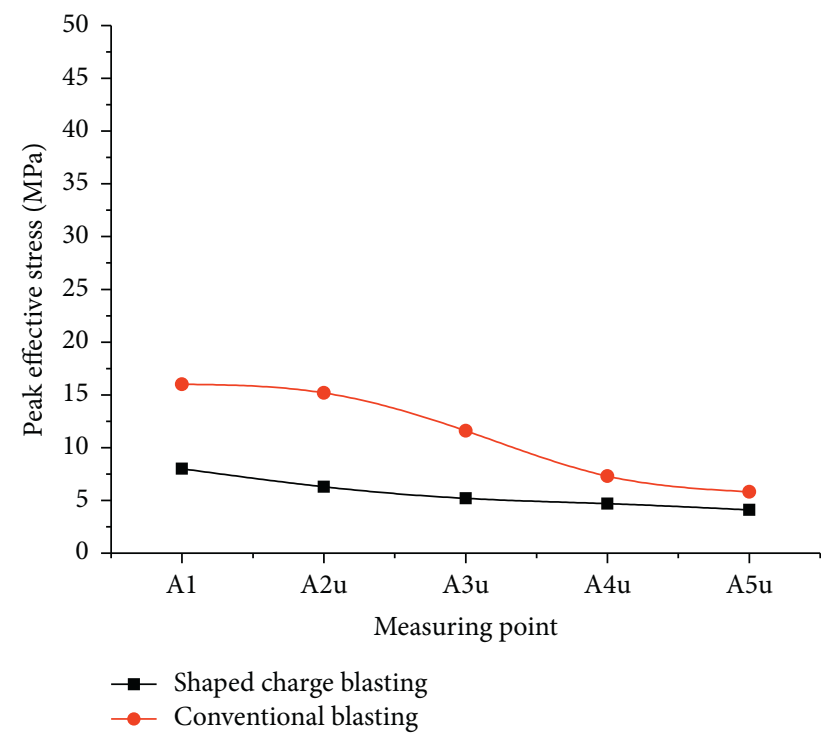

Figure 12: Peak effective stress of measuring point at the vertical direction of the blast hole center line.

shown in Figure 10. Generally speaking, there are more multidirectional cracks produced by ordinary blasting, and the two hole cracks are not connected to the two hole centerline, which is easy to cause over-under-excavation problem. There are fewer cracks produced by shaped charge blasting. The two hole cracks are connected to the two hole centerline, and the crack directional development effect is good.

\subsection{Comparative Analysis of Effective Stress at Measuring} Points. The peak effective stress of each measuring point of shaped charge blasting and ordinary blasting is shown in Figures 11 and 12. The peak effective stress of A1-A5 on the connecting center line of the blast hole was basically the same as that of B1-B5 on the right side of the blast hole. The peak effective stress is the largest at the wall of the blast hole, and the farther away from the center of the blast hole, the smaller the peak effective stress. The results show that the peak effective stress at the borehole wall of shaped charge blasting is larger than that of ordinary blasting, which is conducive to the development of initial cracks in the concentrating energy direction. In the vertical direction of the blast hole center line, the peak effective stress of the measuring point of ordinary blasting is always larger than that of shaped charge blasting, which shows that shaped charge blasting can reduce the damage of rock in the nonconcentrated energy direction. The crack development in the later stage of blasting mainly depends on the effect of blasting gas.

\section{Conclusions}

(1) Under ordinary blasting, multidirectional random cracks will be formed, and it is difficult for double holes to form a straight line through, which is easy to cause the problem of overbreak and underbreak.

(2) The blasting of the elliptical bipolar linear shaped charge can effectively form directional cracks. The main crack of blasting mainly develops in tensile fracture mode, and the explosive gas is the important driving force for continuous crack growth.

(3) The elliptical bipolar linear-shaped charge blasting can effectively reduce the damage of the retained rock mass. The crack penetration is carried out along the connecting center line of the two holes, and the effect is significant.

\section{Data Availability}

The data supporting the results of this study can be obtained upon request to the corresponding author.

\section{Conflicts of Interest}

The authors declare that they have no conflicts of interest regarding the publication of this paper.

\section{Acknowledgments}

The authors would like to express the appreciation for the financial supports from the National Natural Science Foundation of China (51678164), the Guangxi Natural Science Foundation Program (2018GXNSFDA138009), the Guangxi Science and Technology Plan Projects (AD18126011), the GDHVPS (2019), and the major project of Guangzhou City Construction College (2020Zzk01).

\section{References}

[1] S. H. Cho, Y. Nakamura, B. Mohanty, H. S. Yang, and K. Kaneko, "Numerical study of fracture plane control in laboratory-scale blasting," Engineering Fracture Mechanics, vol. 75, no. 13, pp. 3966-3984, 2008. 
[2] R. S. Yang, Y. B. Wang, Z. W. Yue et al., "Dynamic behaviors of crack propagation in directional fracture blasting with two holes," Explosion and Shock Waves, vol. 33, no. 6, pp. 631-637, 2013.

[3] R. S. Yang, Y. B. Wang, D. M. Guo et al., "Experimental research of crack propagation in polymethyl methacrylate material containing flaws under explosive stress waves," Journal of Testing and Evaluation, vol. 44, no. 1, pp. 56-60, 2016.

[4] R. S. Yang, Y. B. Wang, H. J. Xue et al., "Dynamic behavior analysis of perforated crack propagation in two-hole blasting," Procedia Earth and Planetary Science, vol. 5, pp. 254-261, 2012.

[5] Y. Wang, "Study of the dynamic fracture effect using slotted cartridge decoupling charge blasting," International Journal of Rock Mechanics and Mining Sciences, vol. 96, pp. 34-46, 2017.

[6] Z. W. Yue, L. Y. Yang, and Y. B. Wang, "Experimental study of crack propagation in polymethyl methacrylate material with double holes under the directional controlled blasting," $F a$ tigue and Fracture of Engineering Materials and Structures, vol. 36, no. 8, pp. 827-833, 2013.

[7] Z. W. Yue, S. C. Zhang, P. Qiu et al., "Influence of charge structures on the slotted cartridge blasting effect," Journal of Vibration and Shock, vol. 37, no. 10, pp. 27-34, 2018.

[8] Z. W. Yue, S. Y. Tian, S. C. Zhang et al., "Expanding law of cracks formed by slotted cartridge blast under unidirectional confining pressure," Journal of Vibration and Shock, vol. 38, no. 23, pp. 186-195, 2019.

[9] Z. W. Yue, X. B. Hu, Z. Y. Chen et al., "Experimental study of effect of uncoupled charge on energy utilization efficiency of explosives," Blasting, vol. 37, no. 3, pp. 34-39, 2020.

[10] Z. W. Yue, S. Y. Tian, and Z. Y. Chen, "Influence of the interval between holes on crack propagation in slit charge blasting," Chinese Journal of Rock Mechanics and Engineering, vol. 37, no. 11, pp. 2460-2467, 2018.

[11] Z. X. Zhang, Y. L. Guo, and L. F. Li, "Study on mechanism of crack growth of cutting seam cartridge blasting," Engineering Blasting, vol. 2, pp. 11-14, 2007.

[12] C. Zhu, M. C. He, X. H. Zhang et al., "Nonlinear mechanical model of constant resistance and large deformation bolt and influence parameters analysis of constant resistance behavior," Rock and Soil Mechanics, vol. 42, no. 7, pp. 1911-1924, 2021.

[13] Q. Wang, M. C. He, S. C. Li et al., "Comparative study of model tests on automatically formed roadway and gob-side entry driving in deep coal mines," International Journal of Mining Science and Technology, vol. 31, no. 4, pp. 591-601, 2021.

[14] Q. Wang, Y. Wang, M. He et al., "Experimental research and application of automatically formed roadway without advance tunneling," Tunnelling and Underground Space Technology, vol. 114, Article ID 103999, 2021.

[15] Y. Luo, Z. W. Sheng, and X. R. Cui, "ApplicAtion study on blasting with linear cumulative cutting charge in rock," Chinese Journal of Energetic Materials, vol. 3, no. 14, pp. 236-241, 2006.

[16] Y. Luo, "Study on application of shaped charge in controlled rock mass blasting technology," Journal of Disaster Prevention and Mitigation Engineering, vol. 27, no. 1, pp. 57-62, 2001.

[17] D. Y. Guo, J. C. Zhao, P. F. Lv, and M. Zhai, "Dynamic effects of deep-hole cumulative blasting in coal seam and its application," Chinese Journal of Engineering, vol. 38, no. 12, pp. 1681-1687, 2016.
[18] D. Y. Guo, J. C. Zhao, C. Zhang, and T. G. Zhu, "Mechanism of empty borehole on coal crack initiation and propagation under deep-hole cumulative blasting in coal seam," Chinese Journal of Rock Mechanics and Engineering, vol. 37, no. 4, pp. 919-930, 2018.

[19] D. Y. Guo, C. Zhang, T. G. Zhu, and J. J. Pan, "Effect of charge structure on deep-hole cumulative blasting to improve coal seam permeability," Chinese Journal of Engineering, vol. 40, no. 12, pp. 1488-1494, 2018.

[20] B. Wu, H. Wei, S. Xu et al., "Analysis of the cracking mechanism of an elliptical bipolar linear-shaped charge blasting," Advances in Civil Engineering, vol. 2021, Article ID 6669704, 12 pages, 2021.

[21] B. Wu, H. Wei, S. Xu et al., "Numerical study of two-way shaped charge blasting with different charge structures," Engineering Blasting, vol. 27, no. 1, pp. 14-21, 2021.

[22] B. Wu, H. Wei, S. Xu et al., "Research on numerical optimization of smooth blasting layer parameters of shaped energy smooth blasting," Nonferrous Metals Engineering, vol. 10, no. 12, pp. 113-121, 2020.

[23] B. Wu, S. Xu, G. Meng et al., "Study on dynamic evolution law of blasting cracks in elliptical bipolar linear shaped charge blasting," Shock and Vibration, vol. 2021, Article ID 5272878, 10 pages, 2021.

[24] K. Zhang, W. Y. Huang, Q. Y. Chen et al., "Mechanism research of directional fracturing of control hole and application," Blasting, vol. 31, no. 1, pp. 16-18, 2014.

[25] N. Meng, Y. Chen, J. Bai, X. Wang, W. Wu, and B. Wu, "Numerical simulation of directional fracturing by shaped charge blasting," Energy Science \& Engineering, vol. 8, no. 5, pp. 1824-1839, 2020.

[26] Q. Li, Y. Liang, K. K. Ren et al., "Experimental study of propagation of directional cracks with shaped charge under blasting load," Chinese Journal of Rock Mechanics and Engineering, vol. 29, no. 8, pp. 1684-1689, 2010.

[27] N. Murphy, M. Ali, and A. Ivankovic, "Dynamic crack bifurcation in PMMA," Engineering Fracture Mechanics, vol. 73, no. 16, pp. 2569-2587, 2006.

[28] Y. L. Che, Study on the Mechanism of Irregular Cartridge and the Damage of Surrounding Rock, China University of Mining and Technology, Xuzhou, China, 2015. 